\title{
Study of High Performance Liquid Chromatography and Turbidimetric Inhibition Immunoassay for HbA1c Analysis in Diabetic Patients with Variant Hemoglobin
}

\author{
Sultana GS ${ }^{\mathrm{a}}$, Khan NZ ${ }^{\mathrm{b}}$, Khuda $Z^{\mathrm{c}}$, Sultana $\mathrm{TA}^{\mathrm{d}}$, Dipta $\mathrm{TF}^{\mathrm{e}}$, Muttalib MA ${ }^{\mathrm{f}}$, Choudhury $\mathrm{S}^{\mathrm{g}}$
}

\begin{abstract}
Background: $H b A_{1} c$ is considered as "gold standard" to evaluate glycemic control in patients with diabetes. Hemoglobin variants are mutant forms of hemoglobin that can occur by genetic changes in specific amino acid that can affect the accuracy of $H b A_{1} c$ measurements. High performance liquid chromatography (HPLC) is the standard method for HbAlc but inaccurate HbAlc values can occur when hemoglobin variants are present in diabetic patient. The aim of our study is to see Turbidimetric Inhibition Immunoassay (TINIA) method can report HbAlc values in diabetic patients with variant hemoglobin when the values are inaccurate on HPLC.

Methods: 7590 diabetic patients were analyzed for HbA1c by HPLC method from BIRDEM General Hospital during December 2013 to January 2014. HbAlc levels were again measured by TINIA method in 50 cases out of 7590 who showed either undetectable / below normal HbAlc levels. Hb electrophoresis confirmed the variant hemoglobin in few cases

Results: 50 cases out of 7590 (0.65\%) had either undetectable / below normal HbA $A_{1}$ levels by HPLC method. Males-26 and females-24; and the ratio was 0.92:1. In 27 cases, $H b A_{1} c$ values were undetectable by HPLC method but in the reportable range by TINIA method. In the other 23 cases, $H b A_{1} c$ levels were below the reportable range $(<4 \%)$ by HPLC method but were in the normal or higher range by TINIA method. On Bland Altman plot, TINIA method did not agree with HPLC method in variant cases.

Conclusion: In South East Asia where Hb variant is high, Low or undetectable HbAlc level by HPLC may be a convenient clue for screening of hemoglobinopathies especially among diabetic population in Bangladesh. All laboratories should have alternative method of HbAlc testing like TINIA along with HPLC for correct determination of glycemic control in variant cases
\end{abstract}

Key words: $H b A_{1} c, H b$ variant, TINIA.

(BIRDEM Med J 2018; 8(2): 114-117)

Author Information

a. Dr. Gazi Sharmin Sultana, Associate Professor of Clinical Pathology, General laboratory, BIRDEM General Hospital

b. Dr. Nadia Zebin Khan, Medical Officer, General laboratory, BIRDEM General Hospital

c. Dr. Zannat -e- Khuda, Scientific Officer, General laboratory, BIRDEM General Hospital

d. Dr. Tanvira Afroze Sultana, Assistsnt Professor, General laboratory, BIRDEM General Hospital

e. Prof. Tashmim Farhana Dipta, Head, Transfusion Medicine and Clinical Hematology, BIRDEM General Hospital.

f. Dr. MA Muttalib, Professor of Biochemistry and Head, General Laboratory, BIRDEM General Hospital

g. Prof. Subhagata Choudhury, Professor of Biochemistry and Director, Laboratory Services Division, BIRDEM General Hospital, Dhaka

Address of Correspondence: Gazi Sharmin Sultana MBBS, M Phil, Associate Professor of Clinical Pathology, Department of Clinical Pathology, Clinical Biochemistry and Hematology, BIRDEM General Hospital, 122 Kazi Nazrul Islam Avenue, Shahbag, Dhaka 1000, Bangladesh e-mail: gsharmin@gmail.com.

Received: August 31, 2017

Accepted: February 28, 2018

\section{Introduction}

$\mathrm{HbA}_{1} \mathrm{c}$ is gold standar to evaluate the degree of glycemic control in diabetic patients. ${ }^{1,2}$ The American Diabetes Associatio recommended an $\mathrm{HbA}_{1} \mathrm{c}$ goal of less than $7 \%$, while the American Association of Clinical Endocrinology recommended less than $6.5 \% .{ }^{3,4}$ A value of less than $6 \%$ indicates good glycemic control over last the three months, but more than $9 \%$ indicates poor control. ${ }^{5}$

Different assay methods are being used to measure the level of the HbAlc. These methods are based on different analytical principles such as immune turbidimetry, cation exchange chromatography , boronate affinity chromatography ${ }^{6,7}$ However, presently, cation exchange performed by HPLC is the most widely used assay method. ${ }^{8}$

Hemoglobin variants are mutant forms of hemoglobin caused by variations in genetics. They usually affect 
the functionality and/or the stability of the hemoglobin molecule. Known variants in our region are $\mathrm{Hb} \mathrm{E}, \mathrm{Hb}$ F, Hb D-Punjab etc. ${ }^{9}$ Hemoglobinipathies create a major public health concern in south asia, with an estimated 17 million $^{2}$ - thalassaemia carriers in india , 8 million carriers in Pakistan, 3 million in Bangladesh and 0.5 million in Sri Lanka. ${ }^{10}$

Haemoglobin variants (e.g. Hbs trait, Hbc trait) and derivatives can affect the accuracy of $\mathrm{HbAlc}$ measurements. ${ }^{8}$ Glycated HbA1c may indicate the value of glycemic control for a diabetic patient for the last 120 days. Any condition that shortens erythrocyte survival e.g. recovery from acute blood loss, hemolytic anemia will falsely lower $\mathrm{HbA} 1 \mathrm{c}$ test results regardless of the assay method used. ${ }^{12}$

The purpose of this study is to see Turbidimetric Inhibition Immunoassay (TINIA) method can report HbA1c values in diabetic patients with variant hemoglobin when the values are inaccurate on Highperformance liquid chromatography (HPLC).

\section{Methods}

This cross-sectional study was performed on stable adult type 2 diabetic patients attending BIRDEM General Hospital from December 2013 to January 2014 after taking ethical clearance. All EDTA blood samples were first analyzed for $\mathrm{HbA}_{1} \mathrm{c}$ by HPLC method using VARIANT-II TURBO- Bio Rad Laboratories (USA). Samples that showed undetectable or below $4 \% \mathrm{HbA}_{1} \mathrm{c}$ levels by HPLC method as well as a variant window on the HPLC chromatogram were selected for comparison with TINIA method using Dade Behring autoanlyzer (USA). Patients with iron deficiency anaemia, uremia or samples showing presence of carbamyl- $\mathrm{Hb}(\mathrm{cHb})$ by HPLC based $\mathrm{HbA}_{1 \mathrm{C}}$ analysis were excluded. Samples were classified into Group I, consisted of samples that showed undetectable levels of $\mathrm{HbA}_{1} \mathrm{c}$ values by HPLC method and Group II, consisted of samples showing $\mathrm{HbA}_{1} \mathrm{c}$ values below the reportable range $(<4 \%)$ by HPLC. Hemoglobin electrophoresis was performed by alkaline method on agarose gel on randomly selected 7 samples that showed undetectable or below $4 \% \mathrm{HbA}_{1} \mathrm{c}$ levels by HPLC method as well as a variant window on the HPLC chromatogram.

Correlation coefficient and linear regression were used to determine whether the presence of hemoglobin variants caused a statistically significant difference $(\mathrm{P}$ $<0.05$ ) in $\mathrm{HbA}_{1} \mathrm{c}$ results measured by HPLC as compared to Turbidimetric Inhibition Immunoassay using SPSS 11.5. Bland Altman Plot was derived using MedCalc Statistical software.

\section{Results}

Among the 7590 samples analyzed within the study period, 50 samples were initially found to show undetectable or below normal $(<4 \%) \mathrm{HbA}_{1} \mathrm{c}$ values by HPLC method. Among the 50 cases, there were 26 males and 24 females with a ratio of $0.92: 1$. Comparison of HPLC and TINIA method was performed on 50 subjects. 27 cases showed undetected level of $\mathrm{HbA}_{1 \mathrm{C}}$ by HPLC $(n=27$, Group I) and 23 cases showed below normal or less than $4 \%\left(n=23\right.$, Group II) $\mathrm{HbA}_{1 \mathrm{C}}$ values and presence of variant window on HPLC chromatogram. On seven randomly selected cases, alkaline electrophoresis showed presence of $\mathrm{HbE}$ in all of the cases. When measured by TINIA method, all the cases in Group I that had undetectable levels of $\mathrm{HbA}_{1} \mathrm{c}$ produced reportable values (Figure 1). The mean $\mathrm{HbA} 1 \mathrm{c}$ in TINIA method was $9.62 \%$ in Group I.

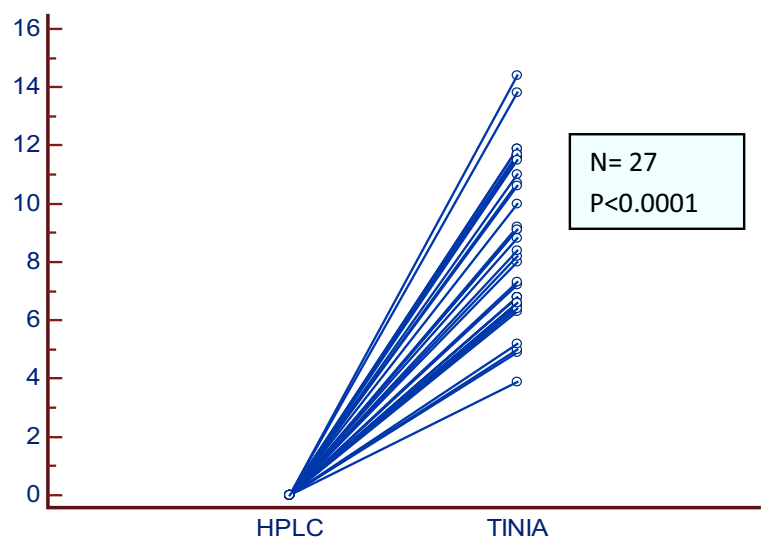

Figure 1. Values of $\mathrm{Hb}_{1}$ c derived by HPLC and TINIA method (Group I). Values are undetectable by HPLC method but within the reportable range by TINIA method.

Group II (23 cases) with below normal $(<4 \%) \mathrm{HbA}_{1} \mathrm{c}$ by HPLC showed reportable values by TINIA method (Figure 2). The difference between the values reported by the two methods were statistically significant $(\mathrm{p}<0.0001)$. The mean HbA1c in HPLC was $3.17 \%$ and in TINIA method was $8.57 \%$. 


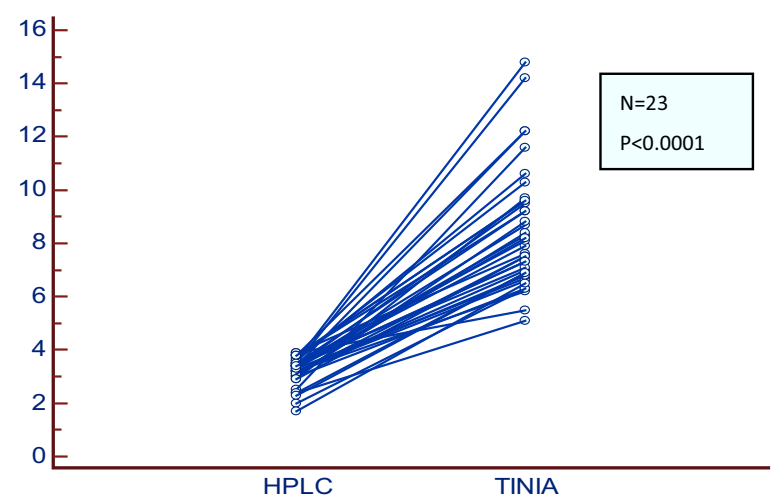

Figure 2. Values of $H b A_{1} c$ derived by HPLC and TINIA method (Group II). Values are below normal $(<4 \%)$ by HPLC method but within the reportable range by TINIA method.

The test results of two methods were plotted on Bland Altman Plot and showed a poor bias of -5.4 (-10.4 to 0.4 ) in $95 \%$ confidence intervals (Figure 3 ) indicating no agreement between two methods.

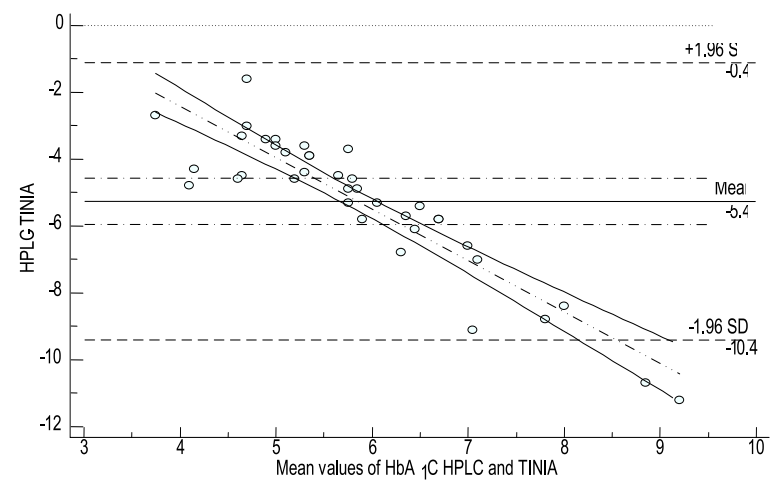

Figure 3. Bland Altman plot of comparison of $\mathrm{HbA}_{1} \mathrm{c}$ values by HPLC with TINIA method among study group (Group I and II). The two methods do not show agreement.

\section{Discussion}

In this study, $\mathrm{HbA}_{1 \mathrm{C}}$ results obtained by Cation Exchange HPLC method were compared with TINIA method. The aim of this study was to evaluate a method with a greater practicability and improved precision in case of diabetic patient with variant hemoglobin where accurate $\mathrm{HbA} 1 \mathrm{c}$ measurements are a challenge. In this study, HPLC produced undetectable $\mathrm{A}_{1 \mathrm{C}}$ in 27 cases and below normal results in 23 cases. All the 50 cases showed variant window on HPLC. Hb electrophoresis showed $\mathrm{Hb} \mathrm{E}$ trait in all the patients. In our study hemoglobin variants affect the results obtain by HPLC methods but not TINIA method. Bland Altman Plot was used to calculate the mean difference and agreement between two methodologies. The plot did not show good agreement between two methods in variant cases. The disagreement between HPLC method and TINIA in the presence of hemoglobinopathy was also observed by other researchers. ${ }^{8.13} \mathrm{~A}$ study also showed significantly lower $\mathrm{HbA}_{1 \mathrm{C}}$ values measured by HPLC when compared to the immunoassay, in patients with heterozygous $\mathrm{Hb}$ E. ${ }^{14}$

$\mathrm{HbA}_{1} \mathrm{c}$ is hemoglobin which is glycated at the $\mathrm{N}$-terminal of the $\beta$ chain $\beta[\mathrm{N}$-deoxyfructosylhemoglobin] and is denoted as the $\mathrm{HbA}_{0}$ peak. The area under the peak is proportional to the amount of analyte present. Hemoglobin having an ionic charge similar to either $\mathrm{HbA}_{0}$ or $\mathrm{HbA}_{1} \mathrm{c}$ will co-elute with the respective peak and interfere with the results.

Inaccurate $\mathrm{HbA}_{1 \mathrm{C}}$ values can occur when hemoglobin variants or its glycated derivatives cannot be separated from $\mathrm{Hb} \mathrm{A}_{0}$ or $\mathrm{HbA}_{1 \mathrm{C}}$. Co-elution of the hemoglobin variant with $\mathrm{HbA}_{1 \mathrm{C}}$ will cause gross overestimation of $\mathrm{HbA}_{1 \mathrm{C}}$, while co-elution of the hemoglobin variant with $\mathrm{Hb} \mathrm{A}$, with resolution of the glycated hemoglobin variant from $\mathrm{HbA}_{1 \mathrm{C}}$, will underestimate the $\mathrm{HbA}_{1 \mathrm{C}}$ results ${ }^{10}$. Similar results were found in our study.

Immunoturbidimetric assays on the other hand, quantify $\mathrm{HbA}_{1 \mathrm{C}}$ using antibody-mediated inhibition of latex agglutination. Monoclonal and poly-clonal antibodies (Abs) used in some of these methods recognize the Nterminal glycated amino acid in the context of the first 4 to 10 amino acids of the $\mathrm{Hb}^{2}$-chain. ${ }^{14}$ Any variant that does not result in changes in the first four to $10 \mathrm{~N}$ terminal amino acids of the ${ }^{2}$-chain of $\mathrm{Hb}$ therefore do not affect the results by TINIA method ${ }^{8}$. However, in contrast to ion-exchange chromatography and boronateaffinity methods, principle of immunoturbidimetric assays does not allow the user to recognize spurious alterations in $\mathrm{Hb}$ elution profiles or pat-terns. ${ }^{14}$ For these reasons, immunoturbidimetric method selection should be considered cautiously in populations where there is a high prevalence of $\mathrm{Hb}$ variants. 


\section{Limitation}

In this study we did not do $\mathrm{Hb}$ electrophoresis in all patients, so further study should be done by incorporating $\mathrm{Hb}$ electrophoresis in all patients.

\section{Conclusion}

In Southeast Asia where populations have a high prevalence of hemoglobinopathies like $\mathrm{HbE}$, methods for the determination of glycated $\mathrm{Hb}$ must be carefully selected to allow accurate determination of $\mathrm{HbA}_{1} \mathrm{c}$. For the measurement of $\mathrm{HbA}_{1} \mathrm{c} \mathrm{level,} \mathrm{all} \mathrm{laboratories} \mathrm{should}$ offer alternative forms of testing, such as Turbidimetric Inhibition Immunoassay or affinity chromatography besides HPLC for correct determination of glycemic control in variant cases. Proper knowledge of hemoglobin variants affecting the measurements $\mathrm{HbA}_{1} \mathrm{c}$ level is essential, in order to avoid mismanagement of diabetic patients. Low or undetectable $\mathrm{HbA} 1 \mathrm{c}$ level by HPLC may be a convenient clue for screening of hemoglobinopathies.

Conflict of interest: Nothing to declare.

\section{References}

1. American Association of Clinical Endocrinologists medical guidelines for clinical practice for the management of diabetes mellitus. Endocr Pract 2007;13(suppl 1):1-68.

2. Standards of medical care in diabetes. American Diabetes Association, Diabetes Care 2009; 32 (suppl 1):S13-S61.

3. Standard of Medical Care in Diabetes. American Diabetes Association, Diabetic Care 2007; 30:S4-41.

4. American Association of Clinical Endocrinology Diabetes Care Plan Guidelines. Endocr Pract 2011; 17(Suppl 2):6-7.
5. Davidson VL and Sittman DB. Biochemistry (NMS). 3rd ed. Harwal USA; 1994.

6. John WG. Haemoglobin A1C: analysis and standardization. Clin Chem Lab Med 2003; 41: 1199-1212.

7. Little RR, Wiedkeyer HM, England JD, Naito HK, Goldstein $\mathrm{DE}$, editors. Interlaboratory comparison of Glycohemoglobin results: College of American Pathologists survey. Clin Chem 1991;37: 1725-29.

8. Bry L, Chen PC, Sacks DB. Effects of hemoglobin variants and chemically modified derivatives on assays for glycated hemoglobin. Clin. Chem 2001; 47:153-63.

9. Uddin MK, Aziz MA, Sardar MH, Hossain MZ, Bhuya MF, Uddin $\mathrm{MM}$ et al. Electrophoretic pattern of hereditary haemoglobin disorders in Bangladesh, J Dhaka Med. Coll 2010; 19(1) : 39-42.

10. Moddell B, Darlinson M. Global epidemiology of hemoglobin disorders and derived service indicators. Bull WHO 2008; 86: $480-87$.

11. Bonavetura J, Riggs A, Hemoglobin Kansas, A Human Hemoglobin with a Neutral Amino Acid Substitution and an Abnormal Oxygen Equilibrium, The Journal of Biological Chemistry 1968 March 10;243: 980-91.

12. Goldstein DE, Little RR, Lorenz RA, Malone JI, Nathan D, Peterson CM: American Diabetes Association Technical Review on Tests of Glycemia. Diabetes Care 1995; 18: 896909.

13. Nasir NM, Thevarajah M, Yean CY . Hemoglobin variants detected by hemoglobin A1c (HbA1c) analysis and the effects on HbA1c measurement. Int J Diabetes Dev Ctries 2010 AprJun; 30(2): 86-90.

14. Chang J, Hoke C, Ettinger B, Penerian G. Evaluation and interference study of he-moglobin A1c measured by turbidimetric inhibition immunoassay. Am J Clin Pathol 1998; 109:274-78 